\title{
Projeto do circuito de acionamento do ignitor de uma bancada de testes de combustores supersônicos
}

\author{
Ignitor drive circuit design of a supersonic combustion test bench
}

Tiago da Costa de Souza ${ }^{1,2}$, Jefte da Silva Guimarães ${ }^{2,3 *}$, Valéria Serrano Faillace Oliveira Leite ${ }^{2,3}$, Dermeval Carinhana Junior ${ }^{2,3}$

\section{RESUMO}

Este projeto tem como objetivo o desenvolvimento do sistema de ignição, controle e aquisição de dados da bancada de testes de combustores supersônicos (BTCS) do Instituto de Estudos Avançados (IEAv), a qual foi projetada para gerar escoamentos com números de Mach de 2 a 3, considerando a vazão e a pressão fornecidas atualmente pela linha de alimentação de gases da bancada. Para isso, deverão ser analisadas as condições necessárias dos gases de alimentação para obtenção do escoamento de testes com os números de Mach desejados, na saída da bancada, para que essas condições de testes, possam ser controladas simplesmente pela manipulação das vazões dos gases de alimentação, na sua entrada.

Palavras-chave: Equipamentos de ensaios em solo, Scramjet, Escoamento supersônico.

\begin{abstract}
This project aims to develop the ignition, control and data acquisition system of the supersonic combustion test bench (BTCS) existing in the Instituto de Estudos Avançados (IEAv), which was designed flows with Mach numbers from 2 to 3 , considering the flow and the pressure provided by the current gas supply line. For this, the necessary conditions of the feed gases must be analyzed to obtain the flow of tests, at the exit of the bench, with the desired Mach numbers, so these test conditions, at the exit of the bench, can be simply controlled by the manipulation of the feed gas flows, at its entrance.
\end{abstract}

Keywords: Ground test facilities, Scramjet, Supersonic flow. 


\section{INTRODUÇÃO}

\section{Veículo Hipersônico}

O veículo aeroespacial com tecnologia scramjet (supersonic combustion ramjet), cujo esquema está mostrado na Fig. 1, utiliza um estato-reator (motor aspirado) que não tem partes móveis e que usa as ondas de choque, formadas na parte frontal do veículo durante o voo hipersônico, para promover a compressão e a desaceleração do ar atmosférico na entrada do combustor. $\mathrm{Na}$ entrada da câmara de combustão, o combustível é injetado e misturado com o oxigênio no ar atmosférico. Como a mistura entra na câmara de combustão em velocidade supersônica, o processo de combustão se dá em regime supersônico, denominada combustão supersônica. O produto da combustão é expelido na região de expansão onde o escoamento é acelerado, criando, dessa forma, o empuxo ${ }^{1}$.

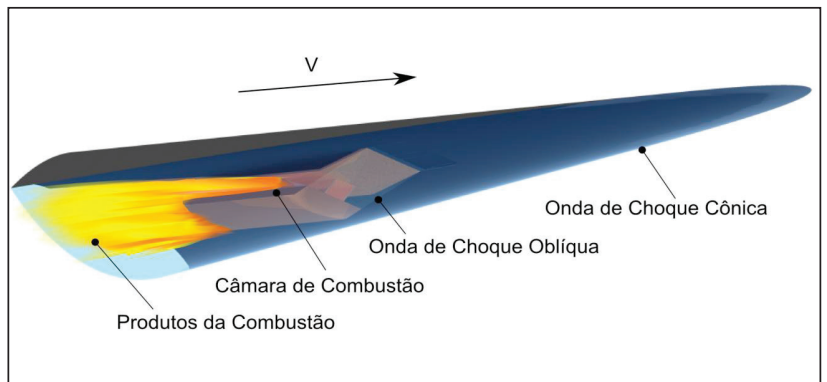

Figura 1: Projeto conceitual de veículo hipersônico com tecnologia scramjet $^{2}$.

\section{Veículo Hipersônico do Instituto de Estudos Avançados (IEAv)}

Para as pesquisas relativas ao veículo demonstrador hipersônico 14-X (Fig. 2), em desenvolvimento no IEAv, são necessários, inicialmente, ensaios em solo que possibilitem a obtenção dos parâmetros do escoamento aos quais o veículo será submetido em um voo real, planejado para atingir as condições de um voo hipersônico com número de Mach 7. Por definição, o número de Mach é dado pela razão entre a velocidade do escoamento $(V)$ e a velocidade do som $(a)^{3,4}$. O número de Mach é um indicador importante no estudo da aerodinâmica, pois, por meio dele, podem ser definidos regimes de velocidade em que se está

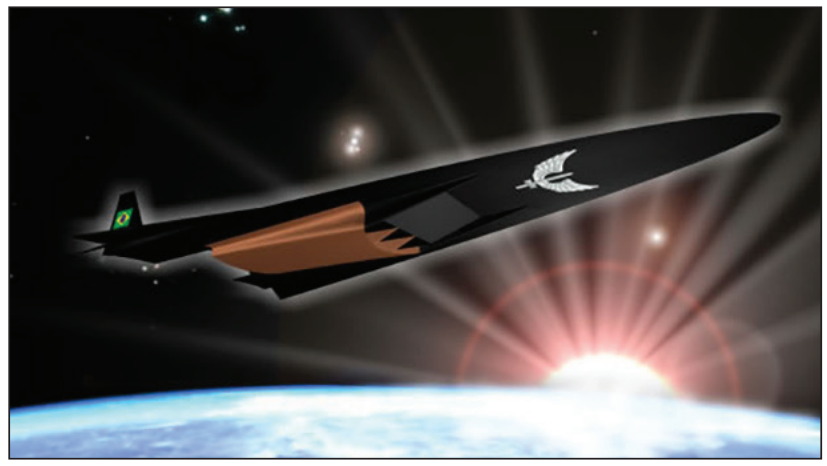

Figura 2: Veículo hipersônico 14-X. trabalhando, sendo eles: o regime subsônico (se $\mathrm{M}<1$ ), o regime sônico (se $M=1$ ) e o regime supersônico (se $M>1$ ). Cada um desses três regimes apresenta suas características individuais. Outras duas definições de regimes podem ser apresentadas, sendo elas o regime transônico, no qual Mach pode variar um pouco abaixo ou acima de $1(0,8 \leq M \geq 1)$, e o regime hipersônico, no qual o valor de Mach é considerado $\mathrm{M}>5^{3,4}$, sendo esse o regime de trabalho do 14-X.

Para realização de ensaios em solo que possibilitem o estudo de escoamentos hipersônicos e da combustão supersônica, o IEAv conta com túneis de choque, com um lançador hipersônico de massa e com uma bancada de testes de combustores supersônicos (BTCS), formando, assim, um conjunto de três equipamentos necessários para realização de ensaios em solo de aerotermodinâmica e hipersônica ${ }^{5}$, sendo que para testes e pesquisas específicas da combustão supersônica foi fabricada, no IEAv, uma BTCS (Fig. 3) que será instalada futuramente no laboratório de ensaios de combustores supersônicos.

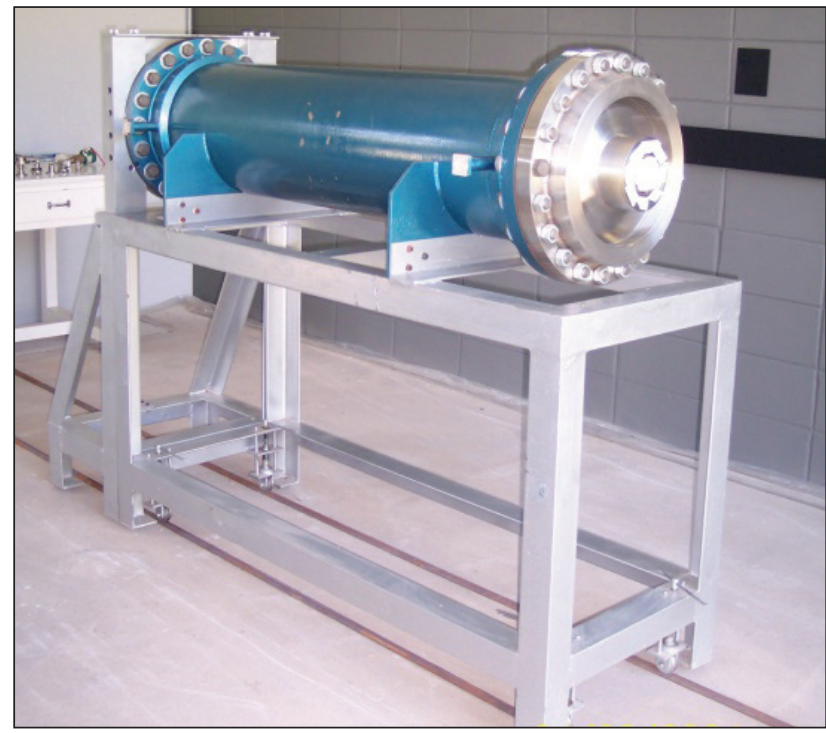

Figura 3: Bancada de Testes de Combustores Supersônicos do IEAv์.

A BTCS consiste, basicamente, de uma câmara de combustão ou gerador de ar viciado (GAV) com uma placa de injeção de combustível (Fig. 4a) em uma extremidade e um bocal supersônico do tipo convergente-divergente (Fig. 4b) na outra. Em uma BTCS, o GAV tem a função de aquecer o ar, e o bocal convergente-divergente tem a função de acelerar o ar aquecido até as condições especificadas para o ensaio ${ }^{7}$. Em um bocal convergente-divergente, a variação do número de Mach ao longo da tubeira é uma função da razão da área transversal $(A)$ em relação à área da garganta $\left(A^{*}\right)$. Essa razão de áreas pode ser determinada pela Eq. $1^{4}$.

$$
\left(\frac{A}{A^{*}}\right)^{2}=\frac{1}{M^{2}}\left[\frac{2}{\gamma+1}\left(1+\frac{\gamma-1}{2}\right) M^{2}\right]^{\frac{(\gamma+1)}{(\gamma-1)}}
$$


A finalidade dessa bancada é produzir, na saída do bocal, as condições do escoamento atrás das ondas de choque cônicas ou oblíquas formadas pelas geometrias frontais, cônica ou em forma de cunha dos demonstradores tecnológicos, voando com velocidades hipersônicas. As condições geradas são as mesmas do escoamento do ar na entrada de um combustor de um scramjet ${ }^{5}$.
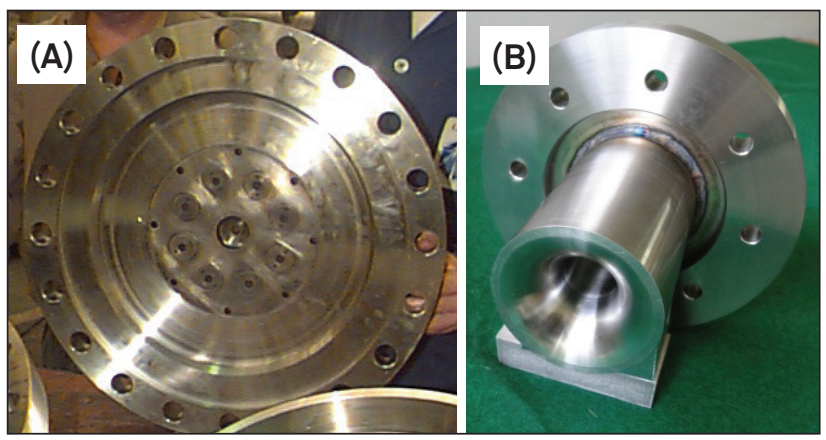

Figura 4: Placa de injeção de combustível (A) e bocal da BTCS (B) do IEAv ${ }^{5}$.

O escoamento gerado pela BTCS é de temperaturas altas, em torno de $1.200 \mathrm{~K}$ (condição gerada pelo GAV) e com velocidades supersônicas em torno de Mach 2,5 (condição gerada pelo bocal na saída da bancada). Na saída do bocal, será futuramente acoplado o combustor a ser testado. Para montagem da BTCS definitiva, é necessária a construção de um laboratório adequado e de uma sala de controle para a segurança dos operadores, bem como um sistema de alimentação de reagentes adequado, incluindo as linhas de ar comprimido, de gás natural veicular (GNV) e de oxigênio. Tendo em vista que o projeto desse laboratório ainda está em desenvolvimento, fabricou-se uma unidade piloto da BTCS (Fig. 5), incluindo um sistema de alimentação de reagentes com vazão adaptada ao volume da nova câmara (Fig. 6). Entretanto, utilizaram-se o mesmo bocal e a mesma placa de injeção de combustível da bancada definitiva, sendo que o bocal utilizado tem garganta de $\varnothing 20 \mathrm{~mm}$ e saída de $\varnothing 34,04$, caracterizando a razão de áreas de 2,89 para número de Mach aproximado de 2,5. Já a placa de injeção de combustível consiste em flange de Ø $200 \mathrm{~mm}$ em aço inox com oito swirlers distribuídos no seu diâmetro.

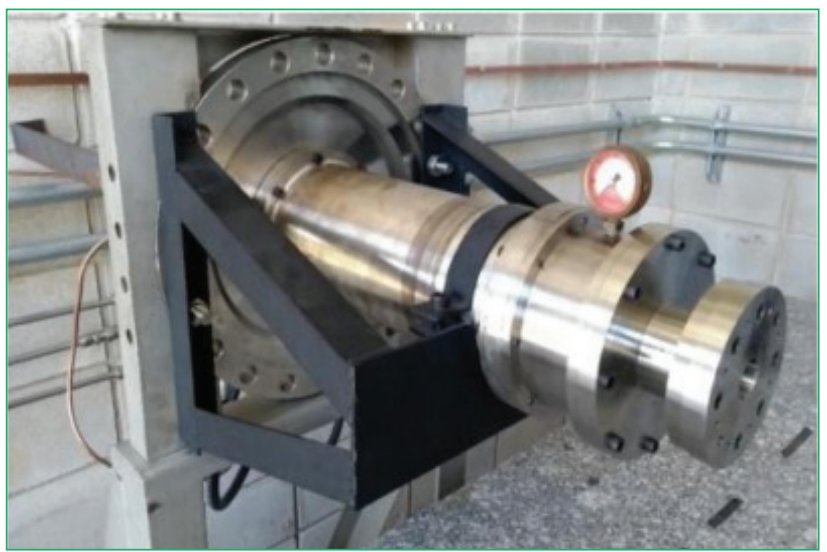

Figura 5: Bancada piloto para testes de combustores supersônicos?

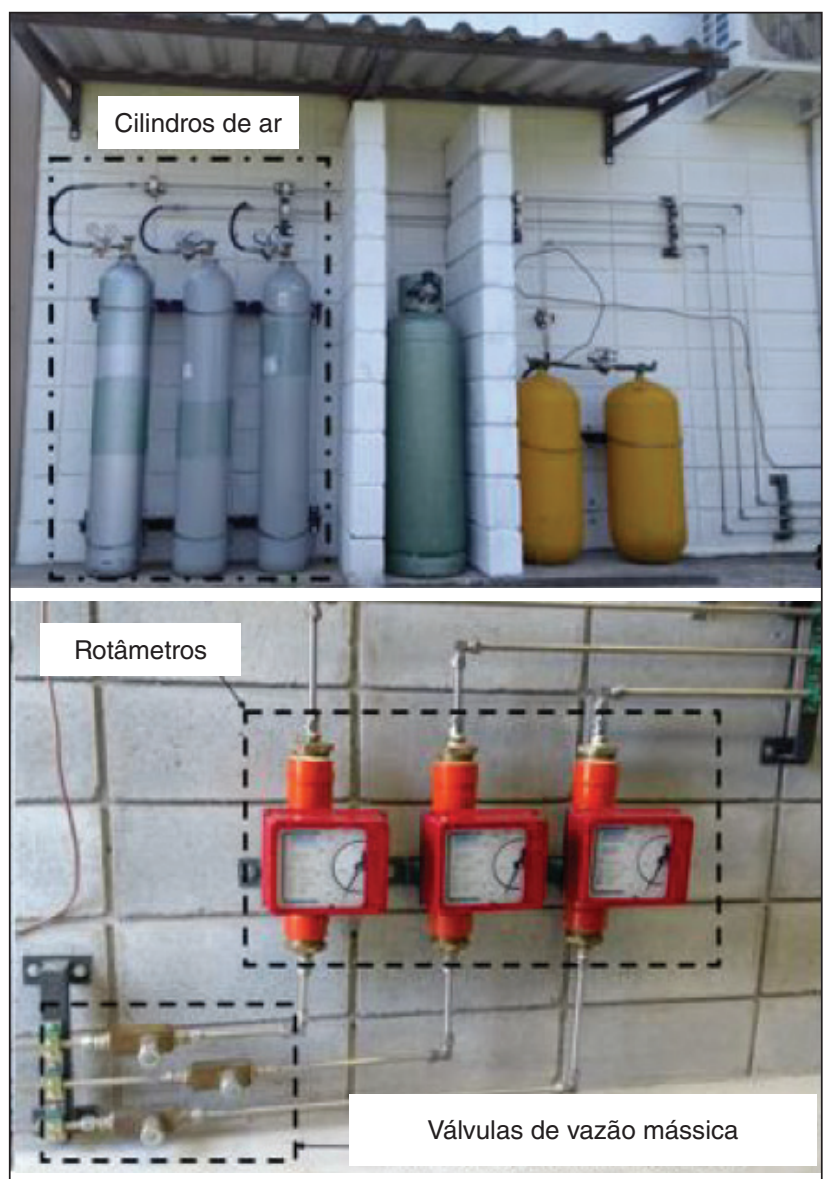

Figura 6: Sistema de alimentação de reagentes da BTCS ${ }^{8}$.

\section{MATERIAIS E MÉTODOS}

Com o desenvolvimento desse projeto, será possível projetar e fabricar um sistema de controle adequado para atender aos objetivos da BTCS do IEAv e aos requisitos de segurança para desenvolvimento da pesquisa.

Para desenvolvimento do acionamento e do sistema de controle e instrumentação, serão utilizados diversos sensores (de pressão, temperatura e outros que forem necessários) e, para determinar a velocidade do escoamento, colocar-se-á, na saída do bocal (tubeira), uma cunha sobre a qual o escoamento supersônico gerado pela saída da tubeira deverá formar uma onda de choque oblíqua. Para visualização do ângulo dessa onda de choque formada sobre a rampa, utilizar-se-á a técnica Schlieren e, com isso, será possível calcular o número de Mach na saída do bocal por meio da equação teta-beta-Mach (Eq. 2) ${ }^{3}$, em que $\theta$ é o ângulo da cunha, $\beta$ é o ângulo de choque formado sobre a cunha e visualizado pela técnica Schlieren e $M$ é a velocidade do escoamento.

$$
\tan \theta=2 \cot \beta \frac{M_{1}^{2} \sin ^{2} \beta-1}{M_{1}^{2}(\gamma+\cos 2 \beta)+2}
$$

O método Schlieren é uma técnica óptica não intrusiva de visualização de escoamentos complexos, baseada no desvio da 
luz ao atravessar um meio transparente que tem gradientes do índice de refração. A deflexão da luz é comparada com a luz não desviada, sendo possível capturar por imagens o desenvolvimento do escoamento9. Com essa técnica, é possível criar contrastes nas imagens que revelam as variações de densidade geradas no escoamento que está sendo estudado. A escolha da técnica Schlieren se deu pelo fato de estudos anteriores ${ }^{7,8}$ demonstrarem que essa metodologia vem sendo viável para aplicações em escoamentos a frio na BTCS, onde o gás utilizado passa a ser apenas o ar comprimido. A Fig. 7 representa um exemplo da determinação do número de Mach em escoamentos a frio na BTCS onde, por meio da técnica Schlieren, é possível visualizar a onda de choque $(\beta)$ sobre uma cunha de ângulo $(\theta)$ conhecido.

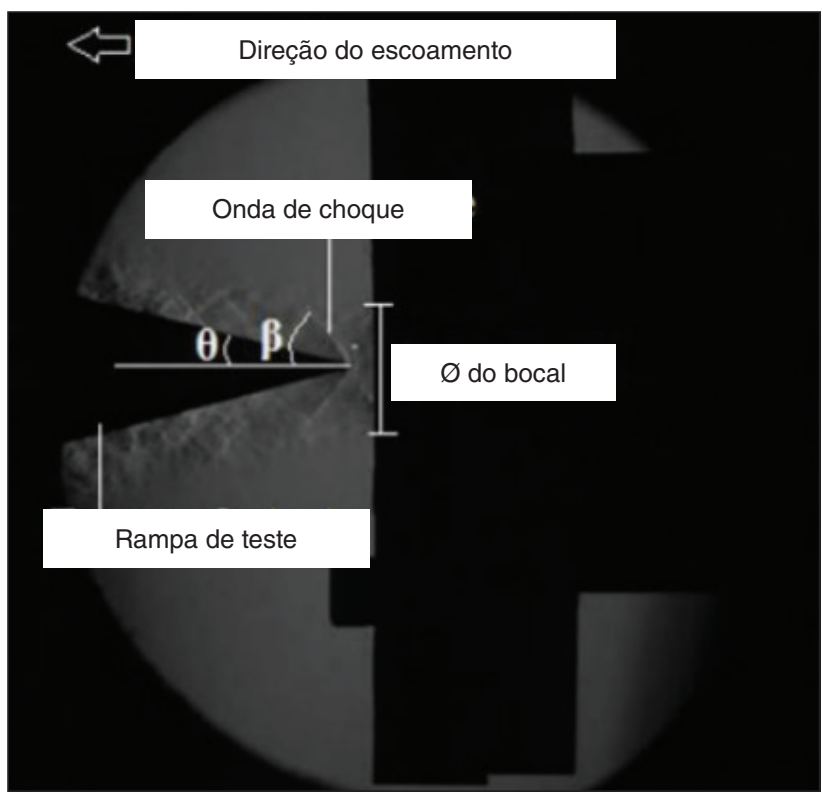

Figura 7: Exemplo da análise do número de Mach por meio da técnica de visualização Schlieren em escoamentos a frio?.

\section{Sistema de Ignição}

O sistema de ignição, nesse primeiro momento, será composto de uma bobina asfáltica, vela e cabo de vela (Fig. 8). Será responsável por acender a chama piloto da BTCS, por meio da ignição do gás liquefeito de petróleo (GLP) que, por sua vez, fará a ignição da mistura de ar atmosférico e GNV.

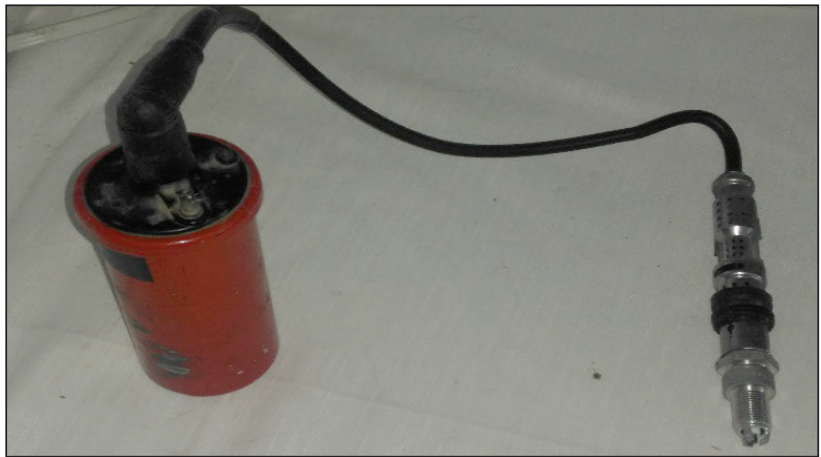

Figura 8: Bobina asfáltica, cabo de vela e vela de ignição.

\section{Medição dos Enrolamentos da Bobina}

Para o projeto do circuito do sistema de ignição, realizaramse algumas medições nos dois enrolamentos da bobina asfáltica (primário e secundário, Figs. 9 e 10) para o correto dimensionamento dos componentes do circuito.

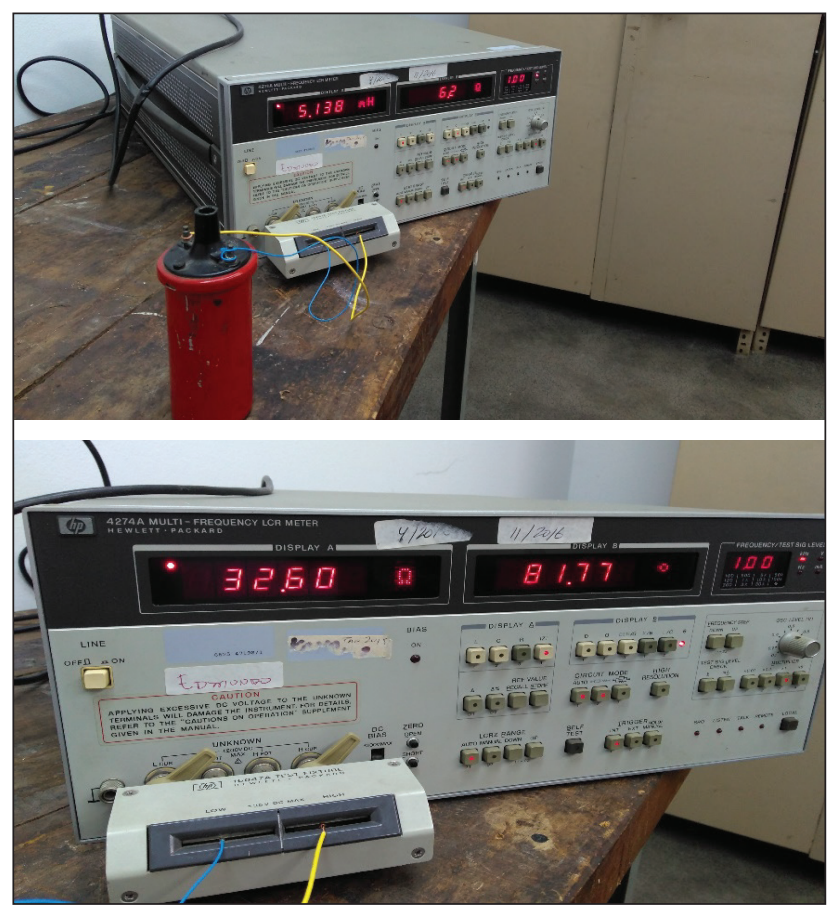

Figura 9: Medição do enrolamento primário e sua impedância.

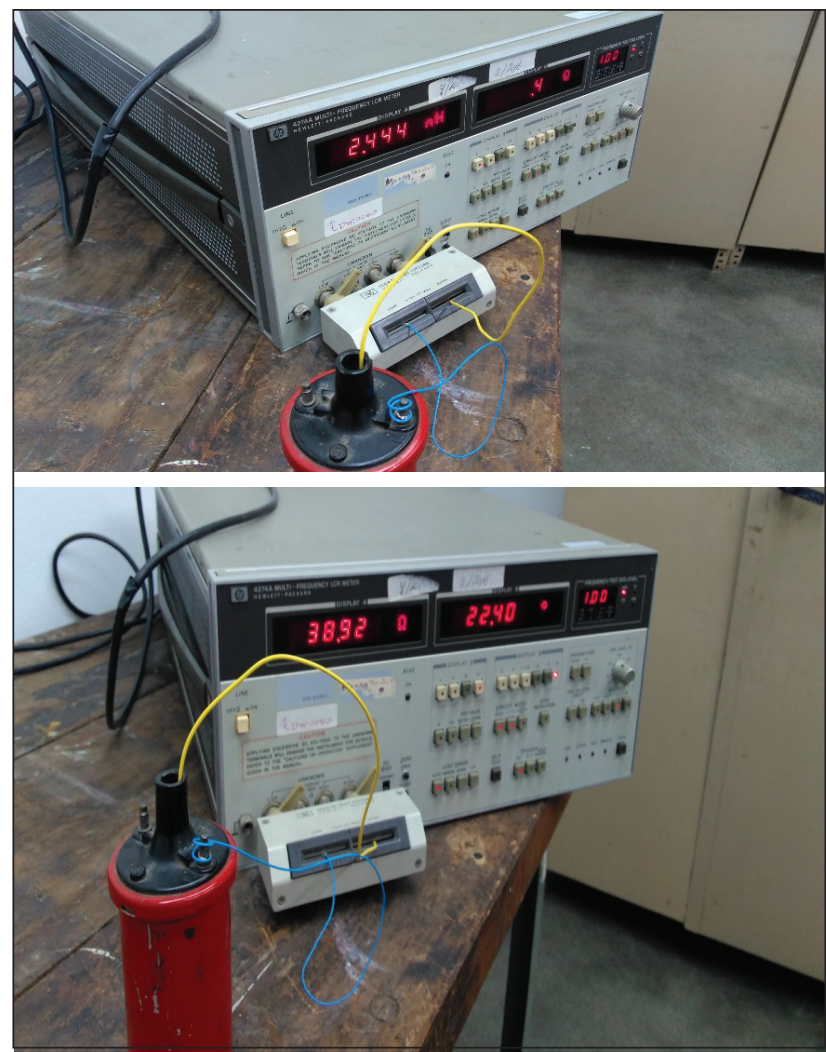

Figura 10: Medição do enrolamento secundário e sua impedância. 


\section{Placa do Circuito Ignitor}

O circuito ignitor (Fig. 11), juntamente com o diagrama elétrico do circuito (Fig. 12), demonstra um pulse width modulation (modulação por largura de pulso) responsável pelo controle de pulsos para a geração do arco da vela durante o tempo em que o botão de acionamento do circuito estiver pressionado. O power width modulation (modulação de largura de potência) controla a largura do pulso gerado pelo circuito de acordo com a amplitude do sinal da referência, que no caso é o sinal de entrada do circuito. A motivação para adotar esse modelo de circuito é garantir que durante todo o ensaio da BTCS não ocorram variações de intensidade da geração dos arcos elétricos e de sua frequência durante a ignição da mistura dos gases que se concentram no interior do GAV. O CI 555 entra no circuito como oscilador (ou multivibrador) na configuração estável, gerando pulsos regulares continuamente, cujos tempos de sinal alto e baixo são determinados pelos demais componentes associados que formam circuitos resistor-capacitor (RC).

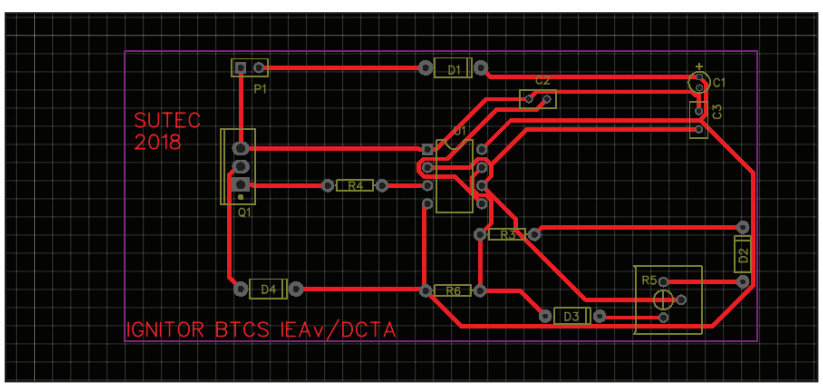

Figura 11: Desenho da placa do circuito pulse width modulation (modulação por largura de pulso).

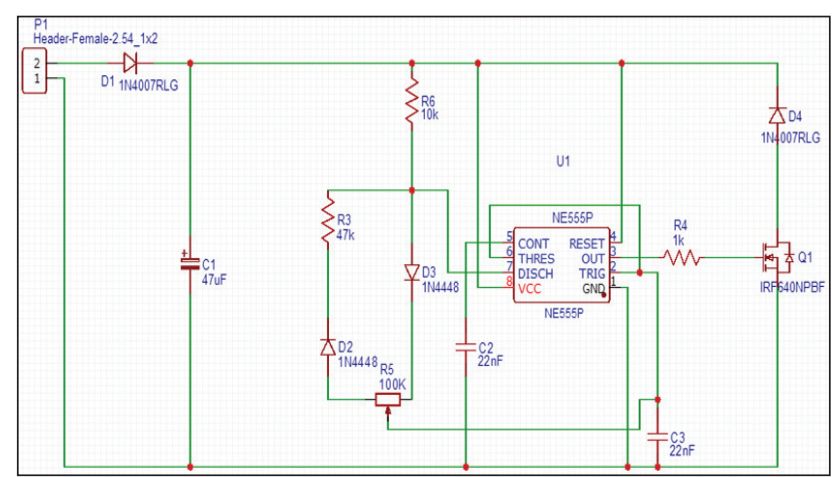

Figura 12: Diagrama elétrico do circuito.

\section{Posicionador da Vela de Ignição}

Foi produzido um flange (Fig. 13) para posicionar a vela de ignição para o acendimento da chama piloto de modo a encontrar uma posição tal que o arco voltaico seja capaz de provocar a ignição do GLP com o menor ciclo de arcos possível.

Com a conclusão do processo de produção do flange, instalouse a vela no alojamento do flange, e o conjunto do posicionador da vela de ignição (Fig. 14) foi instalado na placa de injeção de combustível. A vela foi posicionada de forma que o gás oriundo da válvula piloto passe sobre o arco elétrico gerado na vela através

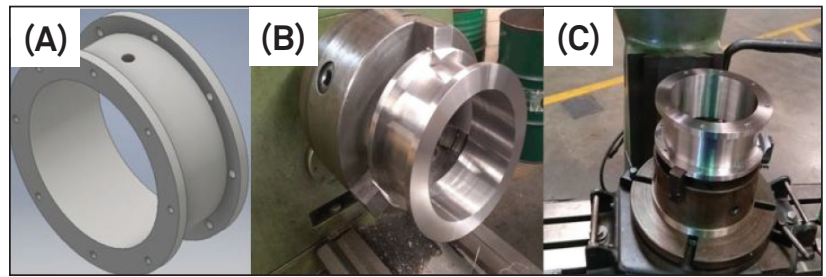

Figura 13: Vista 3D do centro de medições (A), usinagem do centro de medição no torno $(B)$, furação e aberturas de rosca na fresadora $(C)^{8}$.

do circuito montado, ocasionando, assim, a combustão da chama piloto. Uma vez acionada a chama piloto, pode ser liberado o GNV por meio dos swilers instalados na placa de injeção de combustíveis, gerando, dessa forma, a combustão necessária para a formação de um escoamento de alta temperatura que em seguida será acelerado a uma velocidade supersônica pelo bocal convergente-divergente, gerando, assim, as condições necessárias para o ensaio no combustor de um veículo scramjet.

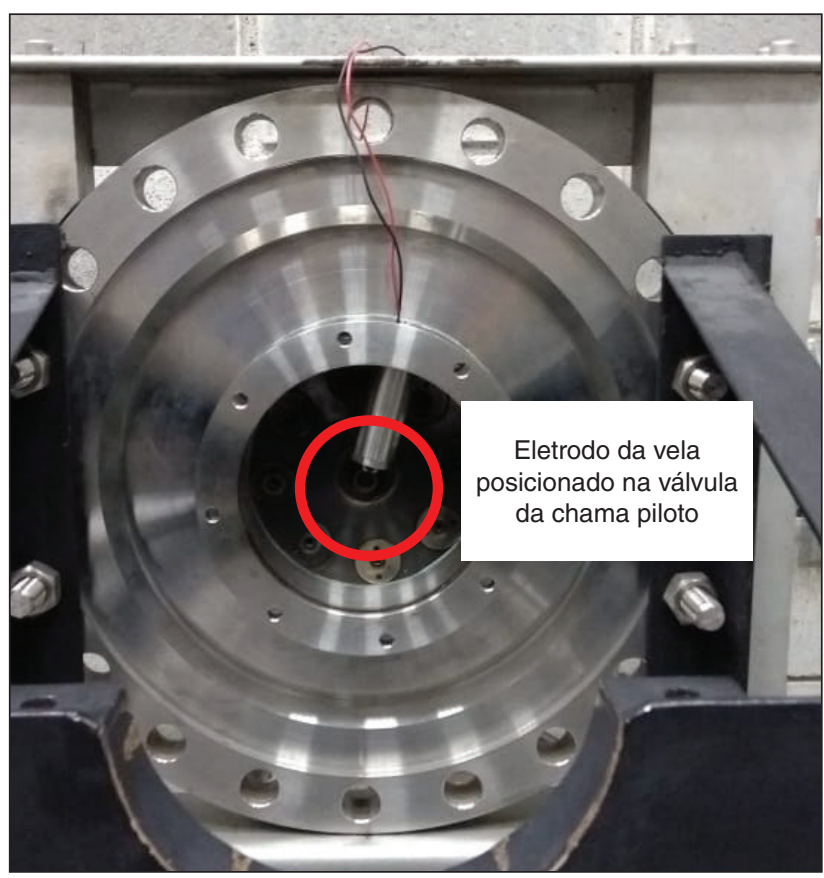

Figura 14: Posicionamento da vela de ignição.

\section{RESULTADOS E DISCUSSÃO}

\section{Ensaio de Funcionamento do Circuito Ignitor}

Durante o ensaio do circuito, verificou-se que seu funcionamento ocorreu conforme o esperado e o ensaio foi validado com o uso de multímetro digital (Fig. 15). Entretanto, não ocorreu a formação doarcovoltaico navela deignição, porfalhanodimensionamentodo cabo de vela, que não era compatível.

Para corrigir a falha, a tensão de $12 \mathrm{~V}$ da fonte foi aplicada diretamente nos polos do eletrodo da vela, por meio da adaptação ilustrada na Fig. 16, e a bobina asfáltica foi substituída por um indutor diretamente no circuito. 


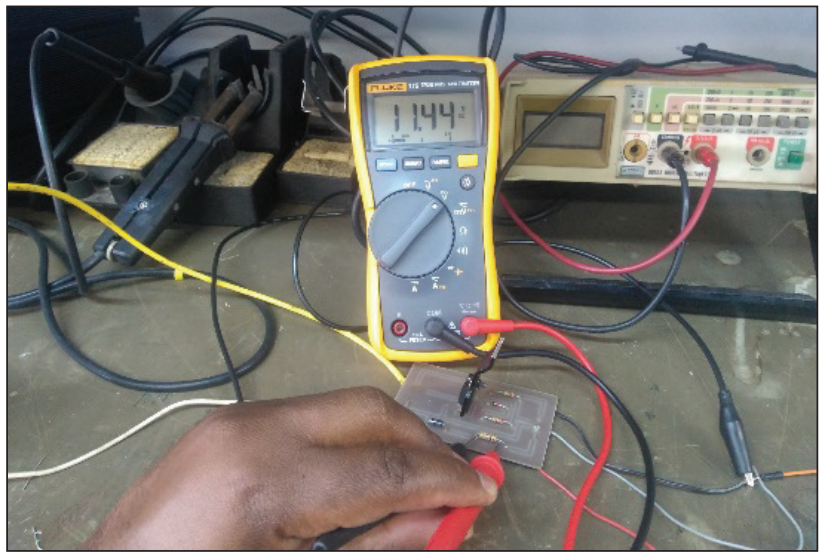

Figura 15: Circuito ensaiado.

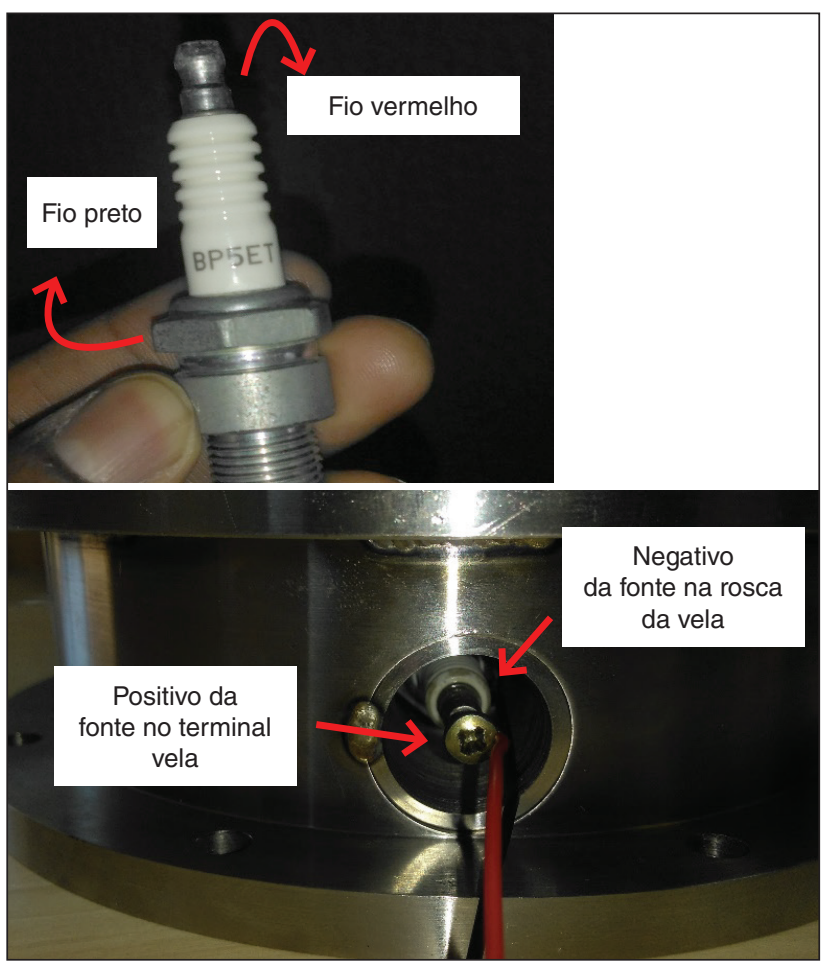

Figura 16: Adaptação da alimentação da fonte sem a bobina asfáltica.

\section{Ignição do GNV Durante Ensaio da BTCS}

\section{Ensaio à pressão atmosférica não confinado (sem câmara)}

Para verificar o comportamento da chama piloto durante ensaio a quente, realizou-se o teste de acendimento da chama piloto por meio da ignição do GNV através do arco gerado pelo ignitor. Com o sistema aberto para a atmosfera e não confinado (Fig. 17), não ocorreu o acendimento.

\section{Ensaio à pressão atmosférica confinado (com câmara)}

Após as tentativas, sem sucesso, de ensaiar a chama piloto sem a câmara de combustão, preparou-se um novo ensaio, com a câmara instalada (Fig. 18), mas aberta para a atmosfera.
Com um circuito ignitor sem oscilador, os ciclos de repetição do arco foram manuais e, após três repetições, ocorreu a ignição do GNV antecedida por uma pequena explosão oriunda do gás acumulado na câmara após as tentativas de ignição.

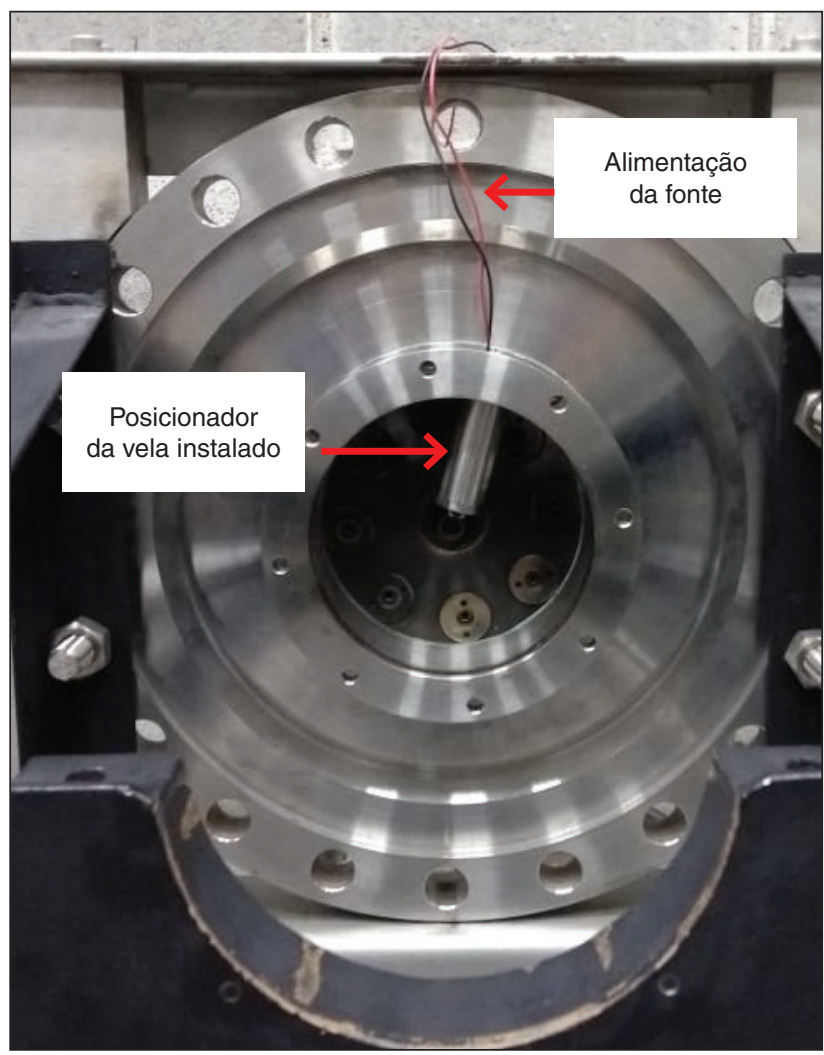

Figura 17: Configuração da BTCS para ensaio não confinado.
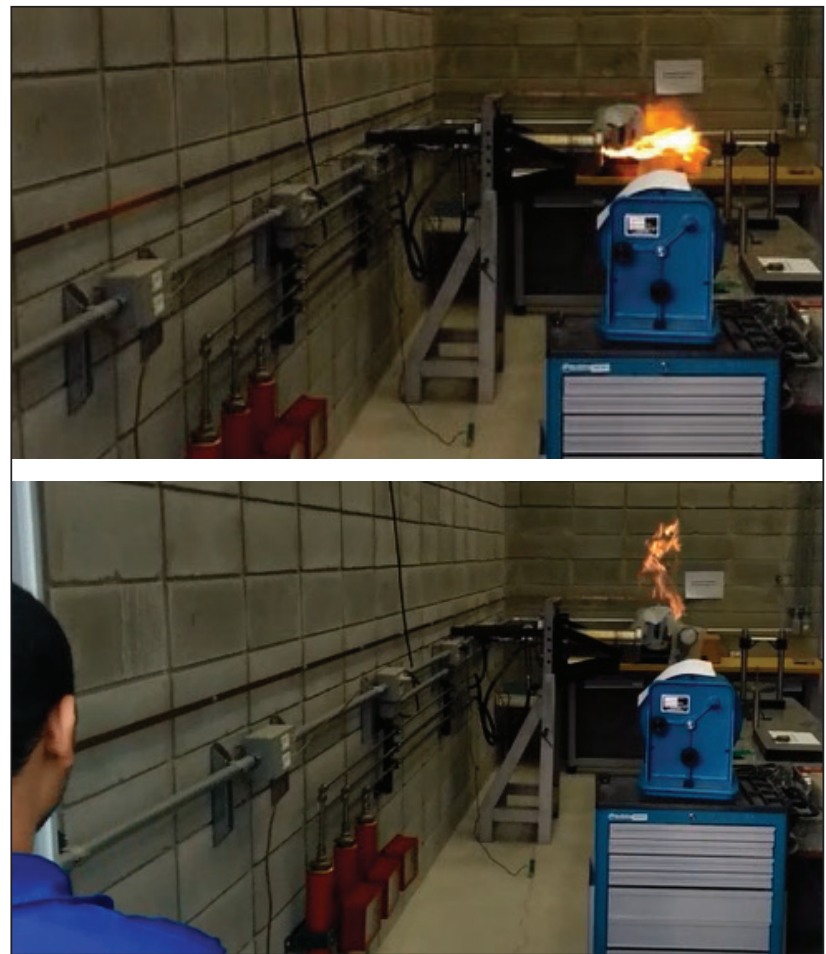

Figura 18: Ensaio da ignição com GNV. 


\section{CONCLUSÕES}

Com o ensaio realizado com o gás GNV, ficou evidenciado que a vela de ignição é adequada para o objetivo dessa missão, devendose considerar, no entanto, que o posicionamento da vela de ignição não era o adequado para uma rápida resposta do sistema e, se mantida nessa posição, poderia alterar os parâmetros durante os demais ensaios de validação do sistema de ignição e aquisição de dados e, futuramente, a validação dos ensaios do scramjet.

Deve-se considerar, também, que o indutor presente no circuito do ignitor, em substituição à bobina asfáltica, pode ter contribuído para a demora da resposta do sistema e, consequentemente, para a ignição do GNV, uma vez que a relação de transformação da bobina asfáltica é de 1:1.000, com power supply elevado ao menos para $12 \mathrm{kV}$, aumentando o calor gerado pelo arco e reduzindo, portanto, o tempo para ignição do gás. Ainda sob essa óptica, não podemos afirmar que a ignição ocorreria perfeitamente na configuração sem câmara, ainda que a vela de ignição estivesse em uma posição ótima definida, pois não foi possível determinar a vazão do gás no momento do ensaio e não ocorreu repetição do ensaio na configuração sem câmara com o ajuste de posição da vela. Uma nova versão do posicionador da vela está sendo fabricada, o que permitirá o ajuste da distância entre a vela de ignição e o bico injetor de GNV, bem como o desenvolvimento do projeto de instrumentação da bancada de testes, que permitirá o controle e o monitoramento da vazão instantânea dos gases durante o funcionamento da bancada.

\section{AGRADECIMENTOS}

Os autores agradecem à Divisão de Suporte Tecnológico e à Divisão de Aerotermodinâmica e Hipersônica do IEAv pelo apoio à realização deste trabalho.

\section{REFERÊNCIAS}

1. Heiser HW, Pratt DT, Daley DH, Mehta UB. Hypersonic airbreathing propulsion. Education Series. Wahhington, DC: American Institute of Aeronautics and Astronautics; 1994. https:// doi.org/10.2514/4.470356

2. Costa FJ da. Projeto dimensional para manufatura do veículo hipersônico aeroespacial 14-X [trabalho de conclusão de curso]. São José dos Campos (SP): Faculdade de Tecnologia de São José dos Campos; 2011.

3. Anderson Junior JD. Modern compressible flow: with historical perspective. 3a ed. New York: McGraw-Hill; 2003.

4. Boles MA, Çengel YA. Thermodynamics: an engineering approach. 8a ed. Pennsylvania: McGraw-Hill; 2015.

5. Leite VSFO, Netto DB. Bancada de testes de combustores supersônicos. Anais do IV Workshop Anual de Pesquisa e Desenvolvimento do Instituto de Estudos Avançados; 2004 jun 14-18; São José dos Campos, Brasil: São José dos Campos: Instituto de Estudos Avançados; 2004.

6. Leite VSFO. Caracterização do escoamento de uma bancada de testes de combustores supersônicos alimentada por ar viciado [tese]. São José dos Campos (SP): Instituto Tecnológico de Aeronáutica; 2006

7. Guimarães JS da, Brandão KMB, Marcos TVC, Leite VSFO, Carinhana DJ. Diagnóstico do escoamento a frio de uma bancada de testes de combustores supersônicos. Anais do Congresso Nacional de Engenharia Mecânica; 2018 maio 2024; Salvador, Brasil. Rio de Janeiro: ABCM; 2018. https://doi. org/10.26678/ABCM.CONEM2018.CON18-0284

8. Guimarães JS da. Investigação do escoamento a frio em uma bancada de testes de combustores supersônicos [dissertação]. São José dos Campos (SP): Instituto Tecnológico de Aeronáutica; 2018

9. Estruch D, Lawson NJ, Garry KP. Application of optical measurement techniques to supersonic and hypersonic aerospace flows. J Aerospace Eng. 2009;22(4)383-95. https:// doi.org/10.1061/(ASCE)0893-1321(2009)22:4(383) 